\title{
Associations of cholesteryl ester transfer protein (CETP) gene variants with pituitary adenoma
}

\author{
Agne Sidaraite $^{\mathrm{a}}$, Rasa Liutkeviciene $\mathrm{e}^{\mathrm{b}, \mathrm{c}}$, Brigita Glebauskiene ${ }^{\mathrm{c}}$, Alvita Vilkeviciute ${ }^{\mathrm{b}}$, Loresa Kriauciuniene $\mathrm{e}^{\mathrm{b}, \mathrm{c}}$
}

\begin{abstract}
Aim. The aim was to evaluate the association of CETP (rs5882 and rs708272) single nucleotide polymorphisms with the presence, invasiveness, hormonal activity and recurrence of pituitary adenoma (PA).

Methods. The study group included 142 patients with PA and the control group, 753 healthy subjects. The genotyping of CETP (rs5882 and rs708272) was performed using a real-time PCR method.

Results. After statistical analysis we found that CETP rs708272 genotype G/A under the over-dominant model was associated with the decreased odds of PA (OR=0.637; $95 \% \mathrm{Cl}: 0.443-0.917 ; P=0.015)$, active $\mathrm{PA}(\mathrm{OR}=0.538 ; 95 \% \mathrm{Cl}$ : $0.335-0.865 ; P=0.01)$ and non-recurrent $\mathrm{PA}(\mathrm{OR}=0.602 ; 95 \% \mathrm{Cl}: 0.402-0.902 ; P=0.014)$. When compared to controls, the rs708272 genotype G/A was less frequent in the active PA subgroup (37.5\% vs $52.7 \%, P=0.009)$ and the non-recurrent PA subgroup ( $40.2 \%$ vs $52.7 \%, P=0.013$ ), while the rs5882 genotype $A / A$ was less frequent in the non-recurrent $P A$ subgroup ( $37.5 \%$ vs $46.2 \%, P=0.015)$.
\end{abstract}

Conclusion. Our study showed that CETP rs708272 genotype G/A may be associated with a decreased risk of PA.

Key words: pituitary adenoma, CETP rs5882, rs708272, gene polymorphism, tumor

Received: November 25, 2018; Accepted with revision: April 4, 2019; Available online: April 17, 2019

https://doi.org/10.5507/bp.2019.016

(c) 2020 The Authors; https://creativecommons.org/licenses/by/4.0/

aLithuanian University of Health Sciences, Medical Academy, Eiveniu 2, Kaunas, Lithuania

${ }^{b}$ Neuroscience Institute, Lithuanian University of Health Sciences, Medical Academy, Eiveniu 2, Kaunas, Lithuania

'Department of Ophthalmology, Lithuanian University of Health Sciences, Medical Academy, Eiveniu 2, Kaunas, Lithuania

Corresponding author: Agne Sidaraite, e-mail: agne.sidaraite@fc.Ismuni.It

\section{INTRODUCTION}

Pituitary adenomas (PAs) are a group of diverse neoplasms which typically arise from adenohypophysis and rarely metastasize ${ }^{1}$. PA accounts for $12-15 \%$ of central nervous system tumors ${ }^{2}$. Women have a two-fold increased risk of developing PA compared to men ${ }^{3}$. PAs are classified according to the type of hormone they produce; if PA does not produce any hormone, it is called inactive PA. Also, PAs can be invasive and noninvasive, recurrent and non-recurrent ${ }^{4}$. Even if PA usually is non-malignant, it tends to recur locally after excision ${ }^{4-5}$. Another problem is the aggressiveness of PA - it does not have a capsule and can grow invasively into surrounding tissues ${ }^{6}$. Not all of these tumors are symptomatic and it is quite hard to diagnose PA while it is in early stages ${ }^{4,7}$. For this reason, scientists are trying to find biomarkers which could help detect PA at early stages ${ }^{1,7}$.

There are familial PAs known, which include multiple endocrine neoplasia type 1 and 4 (MEN1 and MEN4, respectively), Carney complex (CNC) and familial isolated PA (FIPA) (ref. ${ }^{8,9}$ ). However, they make only up to $5 \%$ of all cases of PAs. The vast majority of these tumors arise sporadically and their pathogenesis is a common study object $^{8}$. Some studies were carried out in order to find associations between PA and some genes, such as AIP (10-11), MMP-9 polymorphism ${ }^{12}, M M P-2$ polymorphism ${ }^{13}$, FGFR4 polymorphism ${ }^{14}$ and others.
The cholesteryl ester transfer protein (CETP) gene is located in the $\mathrm{q} 21$ region of chromosome 16 . The product of this gene is a protein of 476 amino acids, which forms a glycoprotein ${ }^{15}$. CETP mediates the exchange of lipids between lipoproteins. This process results in the net transfer of cholesteryl esters from high-density lipoproteins (HDL) to lower-density species, which are atherogenic ${ }^{16-18}$. CETP is synthesized and secreted in many tissues and organs including the brain ${ }^{19}$. It is known that high plasma concentrations of CETP are associated with an increased risk of cardiovascular diseases ${ }^{15-16,20-22}$. CETP could also be associated with many diseases such as neurodegenerative diseases $^{23-28}$, dementia ${ }^{24-26,28}$ and cancer $^{29}$.

The evidence of a possible pathway of tumorigenesis where lipoproteins play a major role is growing. Furberg et al. found that low HDL-C profiles in patients are related to the increased levels of free biologically active estradiol throughout an entire menstrual cycle, especially in women whose body mass index (BMI) is higher. It is known that high levels of estradiol are one of the main risk factors of breast cancer (BC) $\left(\right.$ ref. $\left.^{30}\right)$. Esau et al. have found a $C E T P$-centric cholesterol pathway involved in sensitizing estrogen receptor positive $(\mathrm{ER}+) \mathrm{BC}$ cells to intrinsic mitochondrial apoptosis. Furthermore, analysis of cell line, tissue and patient data from publicly available databases linked elevated CETP expression to cancer, cancer relapse and overall poor survival. The cholesterol pathway constituents, like low-density lipoproteins (LDL) cholesterol, 
cholesterol receptors LDLR and SCARB1 and others, have strong correlation with $\mathrm{BC}$ progression and clinical outcome ${ }^{29-35}$.

We decided to analyze possible associations between CETP and PA because of the growing evidence of CETP involvement in tumor pathogenesis. To our knowledge, this is the first time when such links between PA and CETP are searched.

\section{MATERIALS AND METHODS}

\section{Study and control group formation}

Permission to undertake the study was obtained from the Ethics Committee for Biomedical Research (No P29/2003). The study was carried out in the Department of Ophthalmology and Department of Neurosurgery, Lithuanian University of Health Sciences (LUHS).

Two groups were formed in our study: the pituitary adenoma (PA) group (consisting of 142 patients who were diagnosed with PA) and the control group (consisting of 753 healthy individuals). The inclusion criteria for the PA group were: determined and confirmed PA via magnetic resonance imaging (MRI); good general health condition; consent to participate in the study; age $\geq 18$ years; absence of other brain or any other tumors.

The control group was formed taking into consideration the distribution of age and gender in the PA group. The age median between patients and controls did not differ significantly $(P=0.473)$. Demographic data of the study subjects are presented in Table 1 .

\section{General medical examination}

Data on hypertension, diabetes mellitus, hyperlipidemia, coronary artery disease and stroke were obtained during an examination by a family doctor and gathered from medical records.

\section{Invasiveness evaluation}

PA invasiveness has been described previously ${ }^{36}$. All pituitary adenomas were analyzed based on magnetic resonance imaging (MRI) findings. The preoperative MRI investigations were performed with 1,5 T MRI scanners (Siemens MAGNETOM Avanto, 1,5 T Philips ACHIEVA) using a head coil and a standard pituitary scanning protocol, obtaining T1W sagittal and coronal and T2W/TSE coronal pre-contrast images, and T1W coronal and sagittal gadolinium-enhanced MR images with the intravenous agent gadodiamide (Omniscan, GE Healthcare). The retrospective analysis of MRI data was conducted by an experienced radiologist. The suprasellar extension and sphenoid sinus invasion by PA were classified according to the Hardy classification modified by Wilson ${ }^{37}$. The degree of suprasellar and parasellar extensions was graded as stages A-E. The degree of sellar floor erosion was graded as grades I-IV. Grade III shows localized sellar perforation, and grade IV shows diffuse destruction of sellar floor, which are the signs of invasive PA. The Knosp classification system ${ }^{38}$ was used to quantify the invasion of the cavernous sinus. Grade 3 and 4 pituitary tumors were considered to be invasive.

\section{DNA extraction and genotyping}

Extraction of DNA and analysis of CETP gene polymorphisms (rs5882, rs708272) were carried out in the Laboratory of Ophthalmology, Neuroscience Institute, Lithuanian University of Health Sciences. DNA was extracted from $200 \mu \mathrm{L}$ venous blood (white blood cells) using the silica-based membrane technology utilizing a genomic DNA extraction kit (GeneJET Genomic DNA Purification Kit, Thermo Scientific), according to the manufacturer's recommendations.

The genotyping of CETP polymorphisms (rs5882 and rs708272) was carried out using the real-time PCR. All single-nucleotide polymorphisms (SNPs) were determined using TaqMan ${ }^{\circledR}$ Genotyping assays (Thermo

Table 1. Demographic data for control and PA groups.

\begin{tabular}{|c|c|c|c|}
\hline \multirow[b]{2}{*}{ Characteristic } & \multicolumn{2}{|c|}{ Group } & \multirow[b]{2}{*}{$P$} \\
\hline & $\begin{array}{c}\text { Pituitary adenoma } \\
n=142\end{array}$ & $\begin{array}{l}\text { Control } \\
\mathrm{n}=753\end{array}$ & \\
\hline Age, median, (Interquartile Range) & $53.5(22)$ & $53(0)$ & $0.473 *$ \\
\hline Men, n (\%) & $55(38.7)$ & $274(36.4)$ & \multirow{2}{*}{0.330} \\
\hline Women, n (\%) & $87(61.3)$ & 479 (63.6) & \\
\hline \multicolumn{4}{|l|}{ Invasiveness } \\
\hline Yes & $84(59.15)$ & - & - \\
\hline No & $58(40.85)$ & & \\
\hline \multicolumn{4}{|l|}{ Activity } \\
\hline Yes & $80(56.34)$ & - & - \\
\hline No & $62(43.66)$ & & \\
\hline \multicolumn{4}{|l|}{ Recurrence } \\
\hline Yes & $30(21.13)$ & - & - \\
\hline No & $112(78.87)$ & & \\
\hline
\end{tabular}

*Mann - Whitney test 
Scientific). Genotyping was performed using a RotorGene Q real-time PCR quantification system (Qiagen, USA). Appropriate real-time PCR mixtures of CETP (rs5882, rs708272) were prepared for determining SNPs.

A PCR reaction mixture $(9 \mu \mathrm{L})$ was poured into each of 72 wells of the rotor disc, and then $1 \mu \mathrm{L}$ of matrix DNA of the samples $(\sim 10 \mathrm{ng})$ and $1 \mu \mathrm{L}$ of negative control $(-\mathrm{K})$ were added.

The Allelic Discrimination program was used during the real-time PCR. Then, the assay was continued following the manual provided by the manufacturer (www. qiagen.com, Allelic Discrimination). After that the Allelic Discrimination program was completed and the genotyping results were received. The program determined individual genotypes according to the fluorescence intensity rate of different detectors (VIC and FAM).

\section{Statistical analysis}

Statistical analysis was performed using the SPSS/W 20.0 software (Statistical Package for the Social Sciences for Windows, Inc., Chicago, Illinois, USA). Data are expressed as absolute numbers with percentages. Frequencies of genotypes are expressed in percentages.

Hardy-Weinberg analysis was performed to compare the observed and expected frequencies of CETP SNPs (rs5882, rs708272) using the $\chi^{2}$ test in all groups. The distribution of CETP SNPs (rs5882, rs708272) in the PA and control groups was compared using the $\chi^{2}$ test or the Fisher exact test. Binomial logistic regression analysis was performed to estimate the impact of genotypes on PA development. Odds ratios and 95\% confidence intervals are presented. The selection of the best genetic model was based on the Akaike Information Criterion (AIC); therefore, the best genetic models were those with the lowest AIC values.

For multiple comparisons of the CETP SNPs studied, we used a significance value corrected by the Bonferroni approach. This adjustment was done for CETP SNPs (rs5882, rs 708272) resulting in a 'corrected' significance threshold of $\alpha=0.025(0.05 / 2)$ for genetic data.

Differences were considered statistically significant when $P<0.05$.

\section{RESULTS}

When we compared frequencies of genotypes and alleles in the PA and control groups, we found that the rs5882 G/A genotype was less frequent in the PA group than the control group ( $38 \%$ vs $46.2 \%, P=0.033$ ) while the rs708272 G/G genotype was more frequent in the PA group than the control group (38.7\% vs $29.8 \%$, $P=0.034$ ). The rs708272 genotype $\mathrm{G} / \mathrm{A}$ was less frequent in the PA group than the control group (41.5\% vs $52.7 \%$, $P=0.015$ ) and only this result remained significant after the Bonferroni correction (Table 1 in the supplementary material).

We performed binomial logistic regression analysis of patients with PA and control group subjects. Only overdominant variables were statistically significant in the rs5882 polymorphism (OR=0.677; 95\%CI: $0.473-0.971$; $P=0.034$ ) but this result did not survive Bonferroni correction (Table 2). When we analyzed the rs708272 polymorphism, we found that co-dominant $(\mathrm{G} / \mathrm{A} \mathrm{OR}=0.605$; 95\%CI: 0.405-0.905; and A/A OR=0.864; 95\% CI: 0.522$1.429 ; P=0.043)$, dominant $(\mathrm{OR}=0.670$; 95\%CI: $0.462-$ $0.972 ; P=0.035$ ) and over-dominant $(\mathrm{OR}=0.637 ; 95 \% \mathrm{CI}$ : $0.443-0.917 ; P=0.015$ ) variables were statistically significant but only the latter result remained significant after the Bonferroni correction (Table 2).

We compared frequencies of genotypes and alleles in the invasive and noninvasive PA subgroups and did not find any significant results. We also compared each subgroup by invasiveness with the control group and we found that the rs5882 genotype A/A was less frequent in the noninvasive PA subgroup than in controls ( $32.8 \%$ vs $46.2 \%, P=0.047)$, while the rs708272 genotype G/A was less frequent in the invasive PA subgroup than in the control group (40.5\% vs $52.7 \%, P=0.043)$. The rs 708272 genotype $\mathrm{G} / \mathrm{G}$ was more frequent in the invasive PA subgroup than in control subjects $(40.5 \%$ vs $29.8 \%, P=0.033)$. Unfortunately, all these results did not survive after the Bonferroni correction (Table 2 in the supplementary material).

After binomial logistic regression analysis of patients with invasive and noninvasive PA and control group sub-

Table 2. Binomial logistic regression analysis of patients with PA and control group subjects.

\begin{tabular}{|c|c|c|c|c|c|}
\hline \multicolumn{3}{|c|}{ Genotype, allele } & \multirow{2}{*}{$\frac{\text { OR }(95 \% \text { CI })}{1.439(0.745-2.781)}$} & \multirow{2}{*}{$\frac{P}{0.105}$} & \multirow{2}{*}{$\frac{\mathrm{AIC}}{782.497}$} \\
\hline \multirow{6}{*}{ rs5882 } & Co-dominant & $\mathrm{G} / \mathrm{A}$ & & & \\
\hline & & $\mathrm{A} / \mathrm{A}$ & $0.970(0.495-1.902)$ & & \\
\hline & Dominant & $\mathrm{G} / \mathrm{A}+\mathrm{A} / \mathrm{A}$ & $0.834(0.441-1.579)$ & 0.578 & 784.697 \\
\hline & Recessive & $\mathrm{A} / \mathrm{A}$ & $1.400(0.969-2.023)$ & 0.073 & 781.747 \\
\hline & Over-dominant & $\mathrm{G} / \mathrm{A}$ & $0.677(0.473-0.971)$ & 0.034 & 780.505 \\
\hline & Additive & & $0.856(0.652-1.123)$ & 0.262 & 783.770 \\
\hline \multirow{6}{*}{ rs708272 } & Co-dominant & $\mathrm{G} / \mathrm{A}$ & $0.605(0.405-0.905)$ & 0.043 & 780.703 \\
\hline & & $\mathrm{A} / \mathrm{A}$ & $0.864(0.522-1.429)$ & & \\
\hline & Dominant & $\mathrm{G} / \mathrm{A}+\mathrm{A} / \mathrm{A}$ & $0.670(0.462-0.972)$ & 0.035 & 780.659 \\
\hline & Recessive & $\mathrm{A} / \mathrm{A}$ & $1.156(0.734-1.820)$ & 0.533 & 784.636 \\
\hline & Over-dominant & $\mathrm{G} / \mathrm{A}$ & $0.637(0.443-0.917)$ & 0.015 & 779.031 \\
\hline & Additive & & $0.865(0.665-1.125)$ & 0.280 & 783.845 \\
\hline
\end{tabular}

Values in bold indicate significance after the Bonferroni correction $(P<0.05 / 2)$. 
jects, we found that only in the invasive PA subgroup the rs708272 polymorphism dominant $(\mathrm{OR}=0.623 ; 95 \% \mathrm{CI}$ : $0.392-0.989 ; P=0.045)$ and over-dominant $(\mathrm{OR}=0.610$; 95\%CI: $0.385-0.965 ; P=0.034$ ) variables were statistically significant. Also, these results did not remain significant after the Bonferroni correction (Table 3 in the supplementary material).

After comparison of frequencies of genotypes and alleles in the active and inactive PA subgroups, we did not find any significant results; then compared each subgroup's frequencies with the control group. This analysis showed that the rs5882 genotype G/A was more frequent in the inactive PA subgroup than in the control group ( $58.1 \%$ vs $43.8 \%, P=0.030$ ), while the rs5882 genotype $\mathrm{A} / \mathrm{A}$ was less frequent in the inactive PA subgroup $(32.2 \%$ vs $46.2 \%, P=0.034)$. We also found that the rs 708272 genotype $\mathrm{G} / \mathrm{G}$ was more frequent in the active PA subgroup than in controls ( $41.3 \%$ vs $29.8 \%, P=0.034)$, while the rs708272 genotype G/A was less frequent in the active PA subgroup ( $37.5 \%$ vs $52.7 \%, P=0.009)$. Only the last result remained significant after the Bonferroni correction (Table 4 in the supplementary material).

After binomial logistic regression analysis of the patients with active and inactive PA group and the control group, we found that in the inactive PA group only the rs5882 polymorphism's variables were statistically significant: recessive $(\mathrm{OR}=0.554 ; 95 \% \mathrm{CI}: 0.319-0.962 ; P=0.036)$ and over-dominant $(\mathrm{OR}=1.775$; 95\%CI: 1.050-2.999; $P=0.032$ ) (Table 3). Unfortunately, these results were not significant after the Bonferroni correction (Table 3). We found that in the active PA subgroup the rs708272 codominant $(\mathrm{G} / \mathrm{A}$ : $\mathrm{OR}=0.513$; 95\% CI: 0.305-0.864; and A/A: OR=0.874; 95\% CI:0.469-1.631; $P=0.034)$, dominant $(\mathrm{OR}=0.603 ; 95 \% \mathrm{CI}: 0.376-0.967 ; P=0.036)$ and over-dominant $(\mathrm{OR}=0.538 ; 95 \% \mathrm{CI}$ : $0.335-0.865 ; P=010)$ variables were statistically significant but only the last result survived the Bonferroni correction (Table 3 ).

We compared frequencies of genotypes and alleles be- tween recurrent and non-recurrent PA subgroups and did not find any significant results. We also compared these frequencies between each subgroup by recurrence and the control group and found that the rs5882 genotype A/A was less frequent in the non-recurrent PA subgroup than in controls $(37.5 \%$ vs $46.2 \%, P=0.015)$ and this result remained significant after the Bonferroni correction. The rs708272 genotype $\mathrm{G} / \mathrm{G}$ was more frequent in the nonrecurrent PA subgroup than in the control group (40.2\% vs $29.8 \%, P=0.026$ ), while the genotype $\mathrm{G} / \mathrm{A}$ was less frequent in the non-recurrent PA subgroup than in controls ( $40.2 \%$ vs $52.7 \%, P=0.013$ ). The last result remained significant after the Bonferroni correction (Table 5 in the supplementary material).

After the binomial logistic regression analysis of patients with recurrent and non-recurrent PA and the control group, we found that only in the non-recurrent PA subgroup and in the rs708272 polymorphism there were significant variables: co-dominant $(\mathrm{G} / \mathrm{A}$ : $\mathrm{OR}=0.564$; 95\%CI: 0.362-0.880; and A/A: OR=0.830; 95\% CI: 0.477$1.443 ; P=0.038)$, dominant $(\mathrm{OR}=0.630 ; 95 \% \mathrm{CI}: 0.419$ $0.949 ; P=0.027)$ and over-dominant ( $\mathrm{OR}=0.602 ; 95 \% \mathrm{CI}$ : $0.402-0.902 ; P=0.014$ ) (Table 4). Only the last result survived the Bonferroni correction (Table 4).

\section{DISCUSSION}

To our knowledge, it is the first time that an association between CETP and PA has been searched.

Cholesterol and lipoproteins are two of the most important substances in human body. They are essential for brain maturation and white matter development, and decreased cholesterol early in life may limit both the number and efficacy of synapses. Even though CNS cholesterol concentration does not depend on serum cholesterol lev$\mathrm{els}^{39}$, the changes in serum have been associated with variations in the healthy brain's white matter structure ${ }^{40}$. Also,

Table 3. Binomial logistic regression analysis of patients with active and inactive PAs and control group subjects.

\begin{tabular}{|c|c|c|c|c|c|c|}
\hline & & Genotype, & & OR $(95 \% \mathrm{CI})$ & $P$ & AIC \\
\hline \multirow[t]{2}{*}{ rs5882 } & \multirow[t]{2}{*}{ Inactive } & Recessive & $\mathrm{A} / \mathrm{A}$ & $0.554(0.319-0.962)$ & 0.036 & 435.961 \\
\hline & & Over-dominant & G/A & $1.775(1.050-2.999)$ & 0.032 & 435.922 \\
\hline \multirow[t]{4}{*}{ rs708272 } & \multirow{4}{*}{ Active } & Co-dominant & $\mathrm{G} / \mathrm{A}$ & $0.513(0.305-0.864)$ & 0.034 & 524.002 \\
\hline & & & $\mathrm{A} / \mathrm{A}$ & $0.874(0.469-1.631)$ & & \\
\hline & & Dominant & $\mathrm{G} / \mathrm{A}+\mathrm{A} / \mathrm{A}$ & $0.603(0.376-0.967)$ & 0.036 & 524.655 \\
\hline & & Over-dominant & $\mathrm{G} / \mathrm{A}$ & $0.538(0.335-0.865)$ & 0.010 & 522.182 \\
\hline
\end{tabular}

Values in bold indicate significance after the Bonferroni correction $(P<0.05 / 2)$.

Table 4. Binomial logistic regression analysis of patients with recurrent and non-recurrent PAs and the control group.

\begin{tabular}{|c|c|c|c|c|c|c|}
\hline & Genotype, allel & & & OR $(95 \% \mathrm{CI})$ & $P$ & AIC \\
\hline \multirow[t]{4}{*}{ rs708272 } & Non-recu-rrent & Co-dominant & G/A & $0.564(0.362-0.880)$ & 0.038 & 664.126 \\
\hline & & & $\mathrm{A} / \mathrm{A}$ & $0.830(0.477-1.443)$ & & \\
\hline & & Dominant & $\mathrm{G} / \mathrm{A}+\mathrm{A} / \mathrm{A}$ & $0.630(0.419-0.949)$ & 0.027 & 663.970 \\
\hline & & Over-dominant & $\mathrm{G} / \mathrm{A}$ & $0.602(0.402-0.902)$ & 0.014 & 662.570 \\
\hline
\end{tabular}

Values in bold indicate significance after the Bonferroni correction $(P<0.05 / 2)$. 
cholesterol is used in the essential synthesis of various hormones (estrogen, progesterone and testosterone) for maintaining internal homeostasis ${ }^{41}$. Abnormal cholesterol and lipoprotein levels result in dyslipidemia, which is one of the characteristics of obesity. It includes high levels of triglycerides in very-low-density lipoproteins (VLDL) and low levels of HDL-C (ref. ${ }^{42-44}$ ). The low levels of HDL-C were linked with various types of cancer due to prolonged inflammation which is caused by cytokines, adipokines and hormones ${ }^{44-48}$. Moreover, some authors have found more evidence of the possible pathway of tumorigenesis where lipoproteins play a major role. Furberg et al. have found that low HDL-C profiles in patients are related to the increased levels of free biologically active estradiol throughout the entire duration of a menstrual cycle, especially in women whose body mass index (BMI) was higher. It is known that high levels of estradiol are one of the main risk factors for breast cancer ${ }^{30}$. Li and others have tried to determine if raft levels in human cancer cells differ from normal human cells. They found that breast cancer and the prostate cancer cell lines had more lipid rafts and were more sensitive to cholesterol depletioninduced cell death than normal cells ${ }^{49}$.

Having in mind relations between cancer and lower levels of HDL-C, some studies were performed to find any connection between brain tumors and a higher body mass index ${ }^{50-54}$. Sergentanis et al. have carried out a metaanalysis which showed increased risk of meningioma for obese men and women, while presence of gliomas was associated with a higher BMI for women only ${ }^{54}$. Wiedmann et al. have conducted a large population-based prospective cohort study in which they have found that presence of PA was associated with both overweight (HR 1.39; 95\% CI 1.21-1.61) and obesity (HR 1.43; 95\% CI 1.09-1.88) in men and women, with no significant difference between these two groups ${ }^{55}$.

Some studies were carried out in order to find out if CETP could be associated with Alzheimer's disease (AD) knowing that cholesterol dysregulation is linked with this neurodegenerative disease $\mathrm{e}^{23-28}$. The meta-analysis done by Chen et al. has shown that CETP rs5882 polymorphism could be associated with higher susceptibility to AD (especially in Caucasians) but polymorphism rs 708272 does not play an important role in the pathogenesis of this neurodegenerative disease ${ }^{27}$.

Association between CETP and dyslipidemia is known and studied ${ }^{15-16,20-22}$. Kuivenhoven et al. have proved that CETP rs 708272 polymorphism's B1 allele was linked with higher CETP and lower HDL-C levels ${ }^{16}$. Ridker et al. have carried out a prospective cohort and have found that only single nucleotide polymorphisms near or in the CETP gene were associated with both HDL-C and risk of incident myocardial infarction and the latter risk remained after adjustment for HDL-C (ref. ${ }^{22}$ ). Mirmiran et al. have found that B2 allele carriers had a greater risk of cardiovascular diseases among alcohol drinkers and patients with diabetes ${ }^{15}$.

Only one study has tried to determine if CETP polymorphisms could be associated with cancer. Baez and others have searched for genetic variants which could be linked to gallbladder cancer (GBC) and gallbladder stones $^{56}$ because there are proofs that they are one of the risk factors of this type of cancer ${ }^{57}$. They found that CETP polymorphism rs798272 may be related to gallbladder cancer: the frequency of T/T genotype was higher in gallbladder cancer patients than in gallbladder stone patients ( $\mathrm{OR}=5.04, P=0.012$ ), but when they compared each of these two groups with controls, no significant difference was found. It is hard to make any statements from this study about a possible CETP role in tumorigenesis - it is likely that gallstones play more important role in GBC pathogenesis ${ }^{56}$.

The strength of our study was a thorough examination of the control group - only healthy individuals with no record of present or past hypertension, diabetes mellitus, hyperlipidemia, coronary artery disease, malignant tumors and stroke were included in the control group. Also, the PA group was formed very carefully: invasiveness was evaluated by universally acknowledged classification systems. Our control group was quite large, so the analysis and gathered results were more reliable. The weakness of this study - the cholesterol level and body mass index were not evaluated.

Our study showed that the CETP rs708272 genotype G/A may be associated with a decreased risk of PA and its active and non-recurrent types, while the rs5882 genotype A/A may be linked to a decreased risk of non-recurrent PA. All in all, we can conclude that further research of the mechanisms of PA pathogenesis and of genes involved in this process is needed.

Author contributions: RL, BG, AV, LK: study design; RL, AS, BG, AV, LK performed the research; RL, AV, AS, BG: data analysis and manuscript writing.

Conflict of interest statement: The authors declare that there is no conflict of interest regarding the publication of this paper.

Ethics approval and consent to participate: All procedures performed in studies involving human participants were in accordance with the ethical standards of the institutional and/or national research committee and with the 1964 Helsinki declaration and its later amendments or comparable ethical standards. Permission to undertake the study was obtained from the Ethics Committee for Biomedical Research (No P2-9/2003).

\section{REFERENCES}

1. Theodros D, Patel M, Ruzevick J, Lim M, Bettegowda C. Pituitary adenomas: historical perspective, surgical management and future directions. CNS Oncol 2015;4(6):411-49. doi:10.2217/cns.15.21

2. Page RB. Sellar and parasellar tumors. In: R.H.Wilkins, S.S.Rengachary, editors. Neurosurgery. 2nd ed. Mc Graw - Hill 1996. p.791-804

3. Nistor R. Pituitary tumours. NeuroRew 1996;57:264-72.

4. Lake MG, Krook LS, Cruz SV. Pituitary adenomas: an overview. Am Fam Physician 2013;88(5):319-27.

5. Monteiro ML, Moura FC, Cunha LP. Frequency doubling perimetry in patients with mild and moderate pituitary tumor-associated visual field defects detected by conventional perimetry. Arq Bras Oftalmol 2007;70(2):323-9. 
6. Kovacs K, Scheithauer BW, Horvath E, Lloyd RV. The World health Organization classification of adenohypophysial neoplasms. Cancer 1996;76:502-10.

7. Syro LV, Rotondo F, Ramirez A, Di leva A, Sav MA, Restrepo LM, Serna CA, Kovacs K. Progress in the Diagnosis and Classification of Pituitary Adenomas. Front Endocrinol (Lausanne) 2015;6:97. doi:10.3389/ fendo.2015.00097

8. Vasilev V, Daly A, Naves L, Zacharieva S, Beckers A. Clinical and genetic aspects of familial isolated pituitary adenomas. Clinics 2012;67(Suppl 1):37-41. doi:10.6061/clinics/2012(Sup01)08

9. Schernthaner-Reiter MH, Trivellin G, Stratakis CA. MEN1, MEN4, and Carney Complex: Pathology and Molecular Genetics. Neuroendocrinology 2016;103(1):18-31. doi:10.1159/000371819

10. Hu Y, Yang J, Chang Y, Ma S, Qi J. SNPs in the aryl hydrocarbon receptor-interacting protein gene associated with sporadic nonfunctioning pituitary adenoma. Exp Ther Med 2016;11(3):1142-6. doi:10.3892/etm.2016.3002

11. Barlier $A$, Vanbellinghen JF, Daly AF, Silvy M, Jaffrain-Rea ML, Trouillas J, Tamagno G, Cazabat L, Bours V, Brue T, Enjalbert A, Beckers A Mutations in the aryl hydrocarbon receptor interacting protein gene are not highly prevalent among subjects with sporadic pituitary adenomas. J Clin Endocrinol Metab 2007;92(5):1952-5.

12. Glebauskiene $B$, Liutkeviciene R, Vilkeviciute $A$, Kriauciuniene $L$, Jakstiene S, Zlatkute E, Tamosiunas A, Zemaitiene R, Vaitkiene P, Zaliuniene D. Does MMP-9 Gene Polymorphism Play a Role in Pituitary Adenoma Development? Dis Markers 2017;2017:5839528. doi:10.1155/2017/5839528

13. Glebauskiene $B$, Liutkeviciene $R$, Vilkeviciute $A$, Kriauciuniene $L$, Bernotas G, Tamasauskas A, Zaliuniene D. Role of MMP-2 (-1306 C/T) Polymorphism in Pituitary Adenoma. Scientifica 2016;2016:2839697. doi:10.1155/2016/2839697

14. Tateno T, Asa SL, Zheng L, Mayr T, Ullrich A, Ezzat S. The FGFR4G388R Polymorphism Promotes Mitochondrial STAT3 Serine Phosphorylation to Facilitate Pituitary Growth Hormone Cel Tumorigenesis. Low MJ, ed. PLoS Genet 2011;7(12):e1002400. doi:10.1371/journal.pgen.1002400

15. Mirmiran P, Esfandiar Z, Hosseini-Esfahani F, Koochakpoor G, Daneshpour MS, Sedaghati-Khayat B, Azizi F. Genetic variations of cholesteryl ester transfer protein and diet interactions in relation to lipid profiles and coronary heart disease: a systematic review. Nutr Metab (Lond) 2017;14:77. doi:10.1186/s12986-017-0231-1

16. Kuivenhoven JA, Jukema JW, Zwinderman AH, de Knijff P, McPherson $\mathrm{R}$, Bruschke AV, Lie KI, Kastelein JJ. The role of a common variant of the cholesteryl ester transfer protein gene in the progression of coronary atherosclerosis. The Regression Growth Evaluation Statin Study Group. N Engl J Med 1998;338(2):86-93. doi: 10.1056/ NEJM199801083380203

17. Qiu X, Mistry A, Ammirati MJ, Chrunyk BA, Clark RW, Cong Y, Culp JS, Danley DE, Freeman TB, Geoghegan KF, Griffor MC, Hawrylik SJ, Hayward CM, Hensley P, Hoth LR, Karam GA, Lira ME, Lloyd DB, McGrath KM, Stutzman-Engwall KJ, Subashi AK, Subashi TA Thompson JF, Wang IK, Zhao H, Seddon AP. Crystal structure of cholesteryl ester transfer protein reveals a long tunnel and four bound lipid molecules. Nat Struct Mol Biol 2007;14(2):106-13.

18. Drayna D, Jarnagin AS, McLean J, Henzel W, Kohr W, Fielding C, Lawn R. Cloning and sequencing of human cholesteryl ester transfer protein cDNA. Nature 1987;327(6123):632-4. doi: 10.1038/327632a0

19. Albers JJ, Tollefson JH, Wolfbauer G, Albright RE Jr. Cholesteryl ester transfer protein in human brain. Int J Clin Lab Res 1992;21(3):264-6.

20. Clifford AJ, Chen K, McWade L, Rincon G, Kim SH, Holstege DM Owens JE, Liu B, Müller HG, Medrano JF, Fadel JG, Moshfegh AJ, Baer DJ, Novotny JA. Gender and Single Nucleotide Polymorphisms in MTHFR, BHMT, SPTLC1, CRBP2, CETP, and SCARB1 Are Significant Predictors of Plasma Homocysteine Normalized by RBC Folate in Healthy Adults. J Nutr 2012;142(9):1764-71. doi: 10.3945/ jn.112.160333

21. Rudkowska I, Ouellette C, Dewailly E, Hegele R A, Boiteau V, DubéLinteau $A$, Abdous $B$, Proust $F$, Giguère $Y$, Julien $P$, Château-Degat M-L, Vohl M-C. Omega-3 fatty acids, polymorphisms and lipid related cardiovascular disease risk factors in the Inuit population. Nutr Metab (Lond) 2013;10:26. doi: 10.1186/1743-7075-10-26

22. Ridker PM, Paré G, Parker AN, Zee RYL, Miletich JP, Chasman DI. Polymorphism in the CETP Gene Region, HDL Cholesterol, and
Risk of Future Myocardial Infarction: Genomewide Analysis among 18,245 Initially Healthy Women from the Women's Genome Health Study. Circ Cardiovasc Genet 2009;2(1):26-33. doi: 10.1161/ CIRCGENETICS.108.817304

23. Arias-Vásquez A, Isaacs A, Aulchenko YS, Hofman A, Oostra BA, Breteler $M$, van Duijn CM. The cholesteryl ester transfer protein (CETP) gene and the risk of Alzheimer's disease. Neurogenetics 2007:8(3):189-93. doi: 10.1007/s10048-007-0089-x

24. Rodríguez E, Mateo I, Infante J, Llorca J, Berciano J, Combarros O. Cholesteryl ester transfer protein (CETP) polymorphism modifies the Alzheimer's disease risk associated with APOE epsilon4 allele. J Neurol 2006;253(2):181-5. doi: 10.1007/s00415-005-0945-2

25. Sanders AE, Wang C, Katz M, Derby CA, Barzilai N, Ozelius L, Lipton RB. Association of a functional polymorphism in the cholesteryl ester transfer protein (CETP) gene with memory decline and incidence of dementia. JAMA 2010;303(2):150-8. doi: 10.1001/jama.2009.1988

26. Yu L, Shulman JM, Chibnik L, Leurgans S, Schneider JA, De Jager PL, Bennett DA. The CETP $1405 \mathrm{~V}$ polymorphism is associated with an increased risk of Alzheimer's disease. Aging Cell 2012;11(2):228-33. doi: 10.1111/j.1474-9726.2011.00777.x

27. Chen JJ, Li YM, Zou WY, Fu JL. Relationships between CETP genetic polymorphisms and Alzheimer's disease risk: a meta-analysis. DNA Cell Biol 2014;33(11):807-15. doi: 10.1089/dna.2013.2265

28. Munger $C$, Perkes $A$, Peterson $M$, Schmutz $C$, Leary $M$, Ebbert MT, Ridge PG, Norton MC, Tschanz JT, Munger RG, Corcoran CD, Kauwe JS. Population-based analysis of CETP identifies association between 1405V and cognitive decline: The Cache County Study. Neurobiol Aging 2015;36(1):547.e1-3. doi: 10.1016/j.neurobiolaging.2014.08.022

29. Esau L, Sagar S, Bangarusamy D, Kaur M. Identification of CETP as a molecular target for estrogen positive breast cancer cell death by cholesterol depleting agents. Genes Cancer 2016;7(9-10):309-22.

30. Furberg AS, Jasienska G, Bjurstam N, Torjesen PA, Emaus A, Lipson SF, Ellison PT, Thune I. Metabolic and hormonal profiles: HDL cholesterol as a plausible biomarker of breast cancer risk. The Norwegian EBBA Study. Cancer Epidemiol Biomarkers Prev 2005;14(1):33-40.

31. Nelson ER, Wardell SE, Jasper JS, Park S, Suchindran S, Howe MK, Carver NJ, Pillai RV, Sullivan PM, Sondhi V, Umetani M, Geradts J, McDonnell DP. 27-Hydroxycholesterol links hypercholesterolemia and breast cancer pathophysiology. Science 2013;342(6162):1094-8. doi: $10.1126 /$ science. 1241908

32. Rodrigues dos Santos C, Domingues G, Matias I, Matos J, Fonseca I, de Almeida JM, Dias S. LDL-cholesterol signaling induces breast cancer proliferation and invasion. Lipids Health Dis 2014;13:16. doi: 10.1186/1476-511X-13-16

33. de_Gonzalo-Calvo D, Lopez-Vilaro L, Nasarre L, Perez-Olabarria M, Vazquez T, Escuin D, Badimon L, Barnadas A, Lerma E, LlorenteCortes V. Intratumor cholesteryl ester accumulation is associated with human breast cancer proliferation and aggressive potential: a molecular and clinicopathological study. BMC Cancer 2015;15:460.

34. Kaiser J. Cancer. Cholesterol forges link between obesity and breast cancer. Science (New York, NY) 2013;342(6162):1028.

35. Poirot M, Silvente-Poirot S, Weichselbaum RR. Cholesterol metabolism and resistance to tamoxifen. Curr Opin Pharmacol 2012;12(6):683-9

36. Glebauskiene B, Liutkeviciene R, Vilkeviciute A, Gudinaviciene I, Rocyte A, Simonaviciute D, Mazetyte R, Kriauciuniene L, Zaliuniene D. Association of Ki-67 Labelling Index and IL-17A with Pituitary Adenoma. Biomed Res Int 2018;2018:7490585. doi: $10.1155 / 2018 / 7490585$

37. Wilson CB. Neurosurgical management of large and invasive pituitary tumors. In: Tindall GT, Collins WF, eds. Clinical management of pituitary disorders. New York, NY: Raven. 1979; 335-42.

38. Knosp E, Steiner E, Kitz K, Matula C. Pituitary adenomas with invasion of the cavernous sinus space: A magnetic resonance imaging classification compared with surgical findings. Neurosurgery 1993;33:6108.

39. Saher G, Simons M. Cholesterol and myelin biogenesis. Subcell Biochem 2010;51:489-508. doi: 10.1007/978-90-481-8622-8_18.

40. Williams VJ, Leritz EC, Shepel J, McGlinchey RE, Milberg WP, Rudolph JL, Lipsitz LA, Salat DH. Interindividual variation in serum cholesterol is associated with regional white matter tissue integrity in older adults. Hum Brain Mapp 2013;34(8):1826-41. 
41. Billig H, Furuta I, Hsueh AJ. Estrogens inhibit and androgens enhance ovarian granulosa cell apoptosis. Endocrinology 1993;133(5):220412.

42. Poirier P, Giles TD, Bray GA, Hong Y, Stern JS, Pi-Sunyer FX, Eckel RH. Obesity and cardiovascular disease: pathophysiology, evaluation, and effect of weight loss: an update of the 1997 American Heart Association Scientific Statement on Obesity and Heart Disease from the Obesity Committee of the Council on Nutrition, Physical Activity, and Metabolism. Circulation 2006;113(6):898-918. doi: 10.1161/ CIRCULATIONAHA.106.171016

43. Wang $H$, Peng $D-Q$. New insights into the mechanism of low high-density lipoprotein cholesterol in obesity. Lipids Health Dis 2011;10:176. doi:10.1186/1476-511X-10-176

44. Vucenik I, Stains JP. Obesity and cancer risk: evidence, mechanisms, and recommendations. Ann N Y Acad Sci 2012;1271(1):37-43. doi:10.1111/j.1749-6632.2012.06750.x

45. Drew JE. Molecular mechanisms linking adipokines to obesity-related colon cancer: focus on leptin. Proc Nutr Soc 2012;71:175-80

46. Dalamaga M, Diakopoulos KN, Mantzoros CS. The Role of Adiponectin in Cancer: A Review of Current Evidence. Endocr Rev 2012;33(4):547-94. doi: 10.1210/er.2011-1015

47. Harvey $A E$, Lashinger $L M$, Hursting SD. The growing challenge of obesity and cancer: an inflammatory issue. Ann N Y Acad Sci 2011;1229:45-52. doi: 10.1111/j.1749-6632.2011.06096.x

48. Vílchez JA, Martínez-Ruiz A, Sancho-Rodríguez N, MartínezHernández $\mathrm{P}$, Noguera-Velasco JA. The real role of prediagnostic high-density lipoprotein cholesterol and the cancer risk: a concise review. Eur J Clin Invest 2014;44(1):103-14. doi: 10.1111/eci.12185.

49. Li YC, Park MJ, Ye S-K, Kim C-W, Kim Y-N. Elevated Levels of Cholesterol-Rich Lipid Rafts in Cancer Cells Are Correlated with Apoptosis Sensitivity Induced by Cholesterol-Depleting Agents. Am J Pathol 2006;168(4):1107-18. doi: 10.2353/ajpath.2006.050959

50. Benson VS, Pirie K, Green J, Casabonne D, Beral V. Lifestyle factors and primary glioma and meningioma tumours in the Million Women Study cohort. Br J Cancer 2008;99(1):185-90. doi: 10.1038/ sj.bjc.6604445

51. Michaud DS, Bové G, Gallo V, Schlehofer B, Tjønneland A, Olsen A, Overvad K, Dahm CC, Teucher B, Boeing H, Steffen A, Trichopoulou A, Bamia C, Kyrozis A, Sacerdote C, Agnoli C, Palli D, Tumino R, Mattiello A, Bueno-de-Mesquita HB, Peeters PH, May AM, Barricarte
A, Chirlaque MD, Dorronsoro $M$, José Sánchez M, Rodríguez L, Duell EJ, Hallmans G, Melin BS, Manjer J, Borgquist S, Khaw KT, Wareham N, Allen NE, Travis RC, Romieu I, Vineis P, Riboli E. Anthropometric measures, physical activity and risk of glioma and meningioma in a large prospective cohort study. Cancer prevention research (Philadelphia, Pa) 2011;4(9):1385-92. doi: 10.1158/1940-6207.CAPR-11-0014

52. Wiedmann M, Brunborg C, Lindemann K, Johannesen TB, Vatten $\mathrm{L}$, Helseth $\mathrm{E}$, Zwart JA. Body mass index and the risk of meningioma, glioma and schwannoma in a large prospective cohort study (The HUNT Study). Br J Cancer 2013;109(1):289-94. doi: 10.1038/ bjc. 2013.304

53. Johnson DR, Olson JE, Vierkant RA, Hammack JE, Wang AH, Folsom $A R$, Virnig BA, Cerhan JR. Risk factors for meningioma in postmenopausal women: results from the lowa Women's Health Study. Neuro Oncol 2011;13(9):1011-19. doi: 10.1093/neuonc/nor081

54. Sergentanis TN, Tsivgoulis G, Perlepe C, Ntanasis-Stathopoulos I, Tzanninis IG, Sergentanis IN, Psaltopoulou T. Obesity and Risk for Brain/CNS Tumors, Gliomas and Meningiomas: A Meta-Analysis. Hjelmeland AB, ed. PLoS ONE 2015;10(9):e0136974. doi: 10.1371/ journal.pone.0136974

55. Wiedmann MKH, Brunborg C, Di leva A, Lindemann K, Johannesen TB, Vatten L, Helseth E, Zwart JA. Overweight, obesity and height as risk factors for meningioma, glioma, pituitary adenoma and nerve sheath tumor: a large population-based prospective cohort study. Acta Oncol (Madr) 2017;56(10):1302-9. doi: 10.1080/0284186X.2017.1330554

56. Báez S, Tsuchiya Y, Calvo A, Pruyas M, Nakamura K, Kiyohara C, Oyama M, Yamamoto M. Genetic variants involved in gallstone formation and capsaicin metabolism, and the risk of gallbladder cancer in Chilean women. World J Gastroenterol 2010;16(3):372-8. doi: 10.3748/wjg.v16.i3.372

57. Juvonen $T$, Savolainen MJ, Kairaluoma MI, Lajunen $\mathrm{LH}$, Humphries SE Kesäniemi YA. Polymorphisms at the apoB, apoA-I, and cholesteryl ester transfer protein gene loci in patients with gallbladder disease. J Lipid Res 1995;36:804-12.

\section{Supplemental Material:}

The online version of this article (doi: 10.5507/ bp.2019.016) offers supplemental material. 